Int. J. Plant Sci. 165(1):65-72. 2004.

(c) 2004 by The University of Chicago. All rights reserved.

$1058-5893 / 2004 / 16501-0006 \$ 15.00$

\title{
ECOPHYSIOLOGY AND PLANT SIZE IN A TROPICAL EPIPHYTIC FERN, ASPLENIUM NIDUS, IN TAIWAN
}

\author{
Craig E. Martin, ${ }^{*}$ Teng-Chiu Lin, ${ }^{1} \nmid \dagger$ Chia-Chun Hsu, $\ddagger$ Shin-Hwei Lin, $§$ Kuo-Chuan Lin, $\ddagger$ \\ Yue-Joe Hsia, || and Wen-Liang Chiouł
}

\begin{abstract}
*Department of Ecology and Evolutionary Biology, University of Kansas, Lawrence, Kansas 66045, U.S.A.; †Department of Geography, National Changhua University of Education, 1 Jin-de Road, Changhua 500, Taiwan, Republic of China; ‡Taiwan Forestry Research Institute, 53 Nan-hai Road, Taipei 100, Taiwan, Republic of China; §Department of Soil and Water Conservation, National Chung-Hsing University, 250 Kuo-kwang Road, Taichung 402, Taiwan, Republic of China; and \|Institute of Natural Resources, National Donghwa University, 1, Section 2, Da-hsueh Road, Shou-Feng, Hualien 974, Taiwan, Republic of China
\end{abstract}

\begin{abstract}
Recent studies indicate that, especially in epiphytes, plant size has a strong influence on the ecophysiology of individual leaves of a plant. Extensive data sets that address this phenomenon, however, are limited to a few taxa of flowering plants. It was the purpose of this study to examine numerous physiological parameters in individuals of varying sizes of Asplenium nidus, a widespread epiphytic tropical fern, in a rain forest in northeastern Taiwan. Although stomatal dimensions and frond thickness did not vary with plant size, frond stomatal densities were higher in larger plants. Frond elemental concentration did not vary with plant size for nitrogen, magnesium, phosphorus, and sodium, while the concentrations of carbon, calcium, and potassium changed with plant size, though in different ways. The osmotic concentration of liquid expressed from the fronds did not change with plant size, nor did chlorophyll concentrations and chlorophyll $a / b$ ratio. Fronds excised from smaller plants contained more water yet lost water at lower rates in laboratory drying experiments. Although rates of net $\mathrm{CO}_{2}$ exchange of the fronds measured in situ in the field appeared to increase with plant size, this increase and other size-related differences in gas exchange parameters were not significant. Although some aspects of the ecophysiology of this epiphytic fern varied with changes in plant size, most physiological parameters did not. Thus, the results of this study lend only little support to past findings that plant size is an important consideration in ecophysiological studies of plants.
\end{abstract}

Keywords: ecophysiology, elemental nutrients, epiphytes, gas exchange, morphology, photosynthesis, plant size, Taiwan, water relations.

\section{Introduction}

Plant size is seldom considered in studies of the physiology of intact plants. For example, photosynthetic rates of leaves are not expected to vary dramatically, provided such rates are compared on an equal area or mass basis. Recent studies by Zotz and colleagues, however, indicate that ignoring plant size in physiological studies may lead to erroneous conclusions (Zotz 1997; Schmidt and Zotz 2001; Schmidt et al. 2001; Zotz et al. 2001a, 2001b). They provide convincing evidence that, at least in some epiphytic taxa, physiological parameters of leaves can vary depending on the size of the plant selected for measurement. The bulk of their evidence is derived from ecophysiological investigations of an epiphytic bromeliad, Vriesea sanguinolenta (Schmidt and Zotz 2001), although Schmidt et al. (2001) and Zotz et al. (2001a, $2001 b$ ) provide some evidence that plant size affects the

${ }^{1}$ Author for correspondence; e-mail kuang@ms1.hinet.net

Manuscript received December 2002; revised manuscript received April 2003. physiology of several epiphytic ferns, aroids, and orchids. In addition, results of other studies indicate that plant size, although not always clearly differentiated from plant age, can be an important variable influencing the physiology of terrestrial taxa, particularly trees (Kull and Koppel 1987; Miller et al. 1990; Ryan and Waring 1992; Grulke and Miller 1994; Schoettle 1994; Yoder et al. 1994; Smith and Resh 1999; Kolb and Stone 2000; Grulke and Retzlaff 2001).

The proximal cause of plant size-related differences in the leaf physiology of epiphytes is unclear. Differences in leaf morphology may explain some effects of plant size (Schmidt and Zotz 2001), although Schmidt and Zotz (2001) and Zotz et al. $(2001 a, 2001 b)$ argue that size-related differences in biomass allocation as they relate to plant water relations correlate well with differences in the functioning of plants of different sizes. Clearly, more work is needed to understand the mechanisms underlying differences in physiology that correlate with plant size.

An ideal plant to further examine the relationship between plant size and plant physiology is the epiphytic fern Asplenium nidus found throughout the Old World tropics and subtropics (Huang 1994). Thus far, only one epiphytic fern 


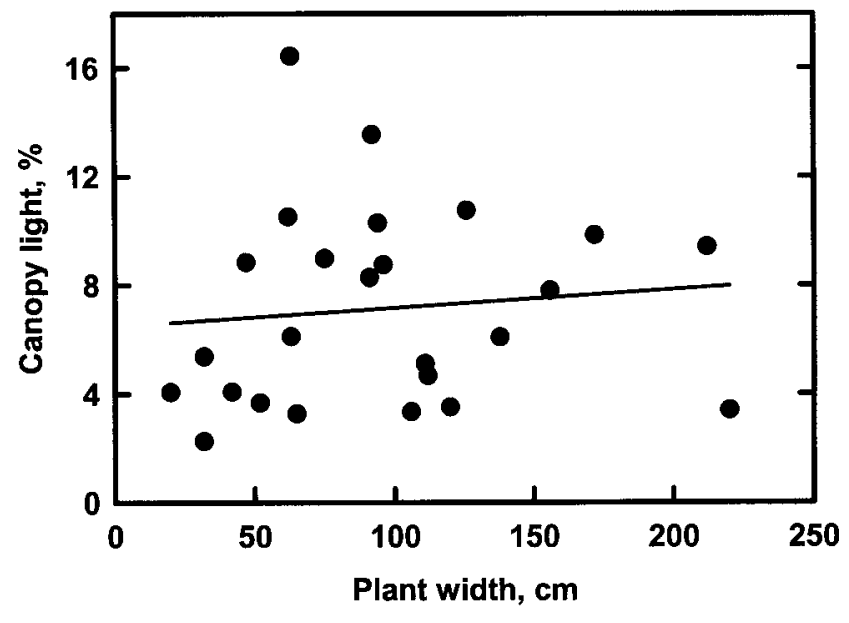

Fig. 1 Percent of canopy light (gap fraction) intercepted by individuals of varying sizes of the epiphytic fern Asplenium nidus in a subtropical forest in northeastern Taiwan. Regression analysis yielded the following: $y=6.48+0.0068 x, r^{2}=0.01, \quad P=0.63$. $n=25$ plants.

(Polypodium crassifolium) has been investigated for sizerelated differences in leaf (frond) physiology (Schmidt et al. 2001). Furthermore, individuals of $A$. nidus reach enormous sizes, up to $2 \mathrm{~m}$ in diameter, yet long-lived individuals of all sizes are easily located in populations of this common and widespread epiphytic fern. Therefore, the goal of this study was to determine whether leaf (frond) physiology varied with plant size in a large population of A. nidus in a subtropical forest in northeastern Taiwan. This is the first study of the size-ecophysiology relationship in an epiphyte using data collected from undisturbed plants in situ.

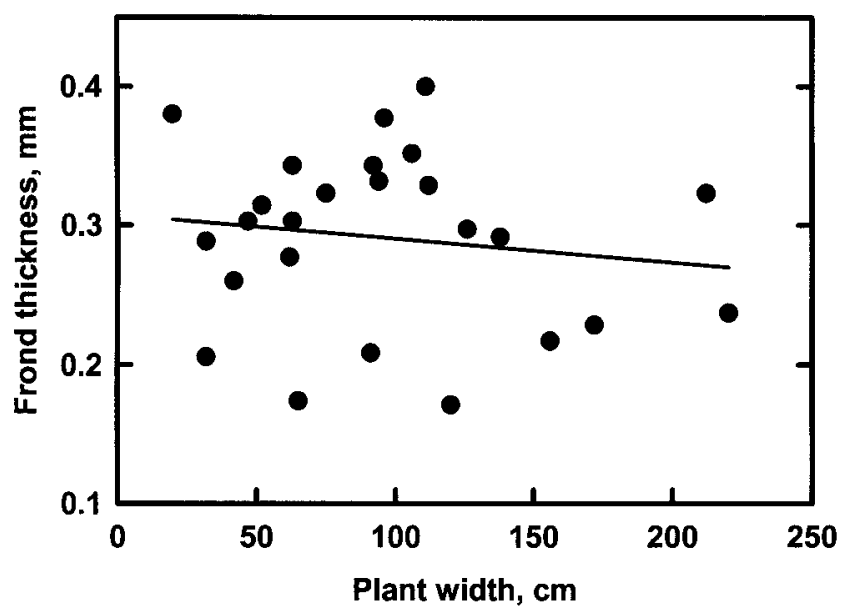

Fig. 2 Thickness of the lamina at the middle of a frond of individuals of varying sizes of the epiphytic fern Asplenium nidus in a subtropical forest in northeastern Taiwan. Regression analysis yielded the following: $y=0.308-0.0002 x, r^{2}=0.02, P=0.50$. $n=25$ plants.

\section{Material and Methods \\ Study Site and Plants}

The study site was a subtropical forest at $600 \mathrm{~m}$ elevation in the Fushan Experimental Forest in northeastern Taiwan (long. $121^{\circ} 34^{\prime} \mathrm{E}$, lat. $24^{\circ} 46^{\prime} \mathrm{N}$ ). Plants were selected in a partially disturbed section of the forest to allow easy accessibility
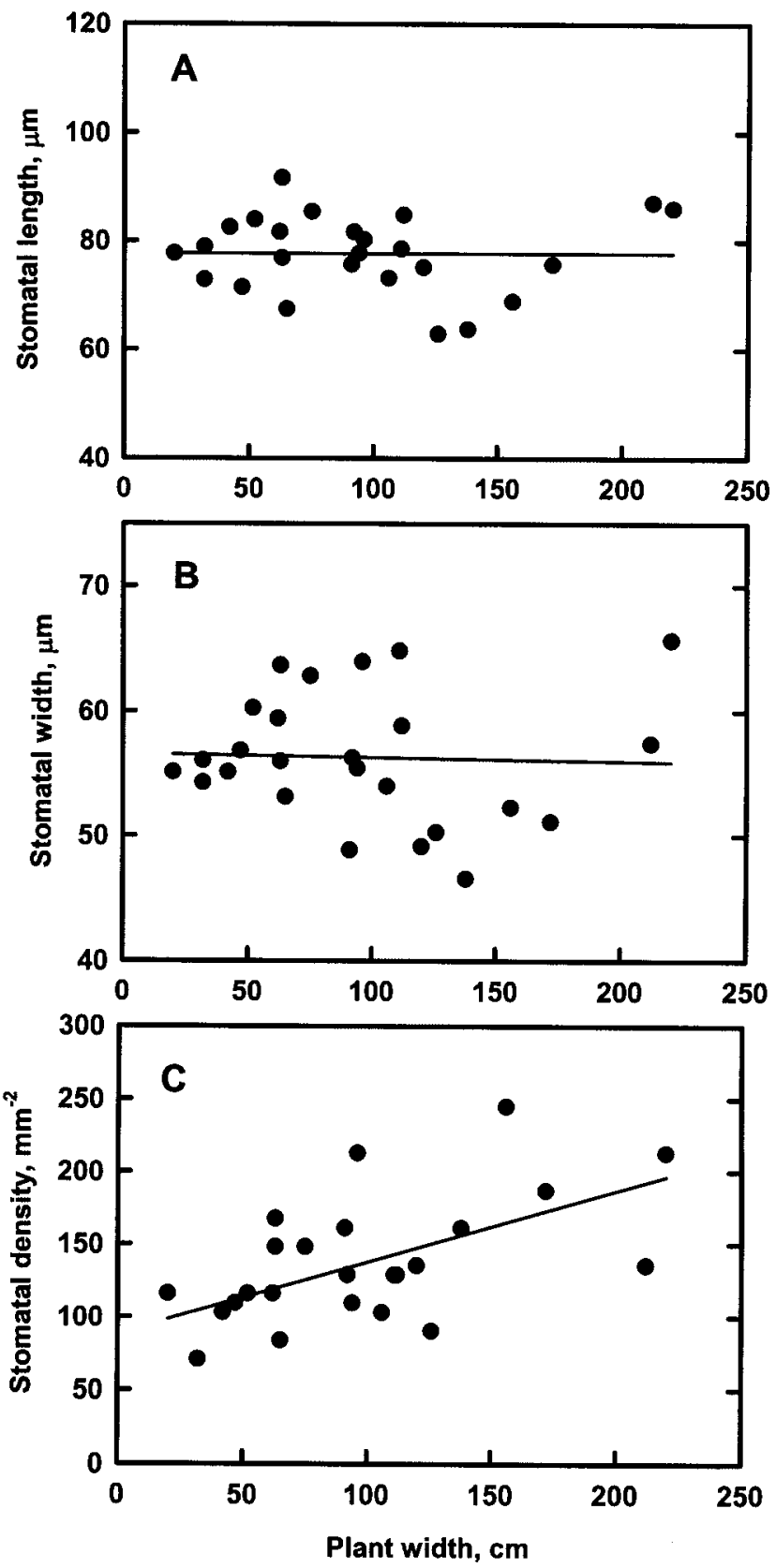

Fig. 3 Stomatal length $(A)$, width $(B)$, and density $(C)$ at the middle of a frond of individuals of varying sizes of the epiphytic fern Asplenium nidus in a subtropical forest in northeastern Taiwan. Regression analysis yielded the following: $A, y=77.7+0.0002 x$, $r^{2}=0, P=0.99 ; B, y=56.6-0.0029 x, r^{2}=0.001, P=0.89 ; C$, $y=88.6+0.49 x, r^{2}=0.35, P=0.002 . n=25$ plants. 
for in situ measurements of leaf gas exchange. The study site included several walking trails and was several hundred meters from the laboratory building. Species of dominant trees at this site were numerous, primarily in the families Fagaceae and Lauraceae; three examples are Litsea acuminata (Bl.) Kurata (Lauraceae), Machilus zuiboensis Hayata (Lauraceae), and Symplocos glauca (Thunb.) Koidz. (Symplocaceae). Climatic conditions at the Fushan site are subtropical, with monthly average air temperatures ranging from $10^{\circ}$ to $25^{\circ} \mathrm{C}$ and monthly rainfall ranging from less than $10 \mathrm{~cm}$ to more than $50 \mathrm{~cm}$, with maxima occurring in the summer months. During the time of measurements for this study (June 16-23, 2001), local environmental conditions were as follows: average air temperature of $23.4^{\circ} \mathrm{C}$ (minimum $20.5^{\circ} \mathrm{C}$, maximum $27.9^{\circ} \mathrm{C}$ ), average air relative humidities (RH) more than $80 \%$, and average daily wind speeds from 1.3 to $3.5 \mathrm{~m} \mathrm{~s}^{-1}$ (maxima ranged from 5.4 to $12.3 \mathrm{~m} \mathrm{~s}^{-1}$ ). Most days were intermittently cloudy without precipitation, although $4.6 \mathrm{~cm}$ of rain fell during the month of June 2001.

Plants were selected for study using three criteria: (1) adequate representation of widely differing plant sizes (five plants were less than $50 \mathrm{~cm}$ wide, five were between 50 and $75 \mathrm{~cm}$ wide, five were between 75 and $100 \mathrm{~cm}$ wide, six were between 100 and $150 \mathrm{~cm}$ wide, and four were wider than $150 \mathrm{~cm})$; (2) location on the host tree within $3 \mathrm{~m}$ of the ground; and (3) similar canopy openness (gap fraction; fig. 1). The latter was measured with a LI-COR LAI-2000 Canopy Analyzer (Lincoln, Neb.), with one sensor held horizontally at the height of the epiphyte and ca. $1 \mathrm{~m}$ from the tree trunk and the other sensor in a clearing. Plant size was measured using a handheld tape measure at the widest diameter of each plant. Although plant size varied greatly, the fronds selected for morphological and physiological measurements on all plants were fully expanded and healthy in appearance. Ages of the fronds and of the plants were unknown. All physiological measurements were made at the vertical midpoint of the rosettes; fronds with spores were avoided. Although samples from 25 plants were included in all analyses, some samples and data were lost, so sample sizes ranged from 20 to 25 .

\section{Frond Morphology}

Frond thickness, stomatal density, and stomatal dimensions were measured on a computer using digitized photomicrographs taken with a Leica DMLB microscope (Mannheim, Germany) using the middle section of a freshly cut mature frond of average length for each plant. Stomatal measurements were made using fingernail polish impressions of the frond surfaces.

\section{Frond Elemental Concentrations}

One mature frond of average length was excised, dried at $65^{\circ} \mathrm{C}$ for at least a week, ground into a powder (particle size less than $0.5 \mathrm{~mm}$ ), and ashed at $490^{\circ} \mathrm{C}$. The ash was extracted with $2 \mathrm{~N} \mathrm{HCl}$ and filtered through a membrane. Calcium, magnesium, phosphorus, potassium, and sodium concentrations of the filtrate were determined using a model
JY2000 inductively coupled plasma emission spectrometer (Jobin-Yvon Horiba Group, Edison, N.J.). A 2-mg sample of the initial powder was used for carbon and nitrogen analysis using a model NA1500 CN analyzer (Thermo Finnigan, San Jose, Calif.).
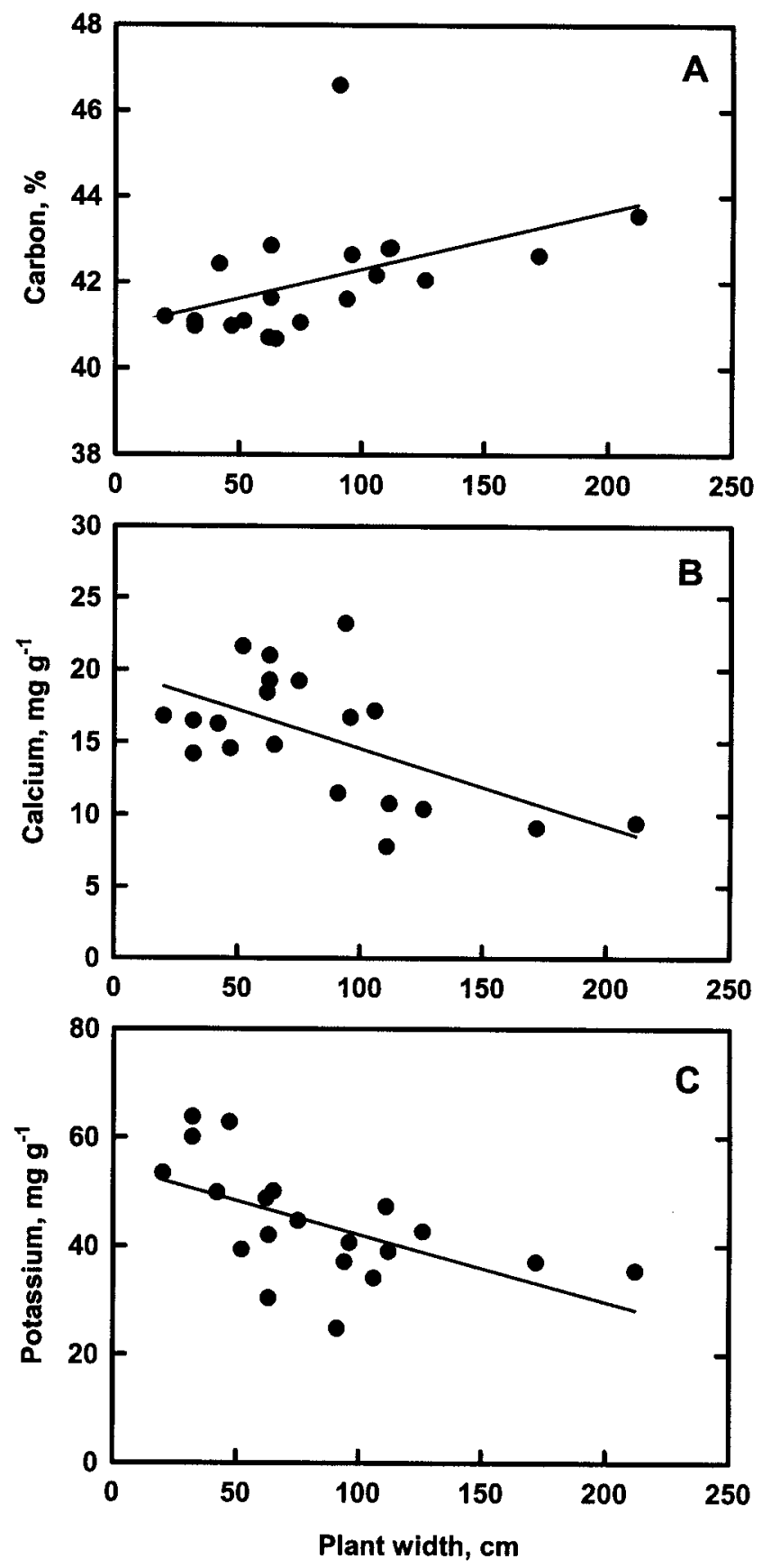

Fig. 4 Percent carbon $(A)$ and concentrations of calcium $(B)$ and potassium $(C)$ of tissue at the middle of a frond of individuals of varying sizes of the epiphytic fern Asplenium nidus in a subtropical forest in northeastern Taiwan. Data are expressed on a dry mass basis. Regression analysis yielded the following: $A, y=40.9+0.0136 x$, $r^{2}=0.23, P=0.03 ; B, y=19.9-0.0536 x, r^{2}=0.33, P=0.008 ; C$, $y=19.9+0.054 x, r^{2}=0.33, P=0.008 . n=20$ plants. 

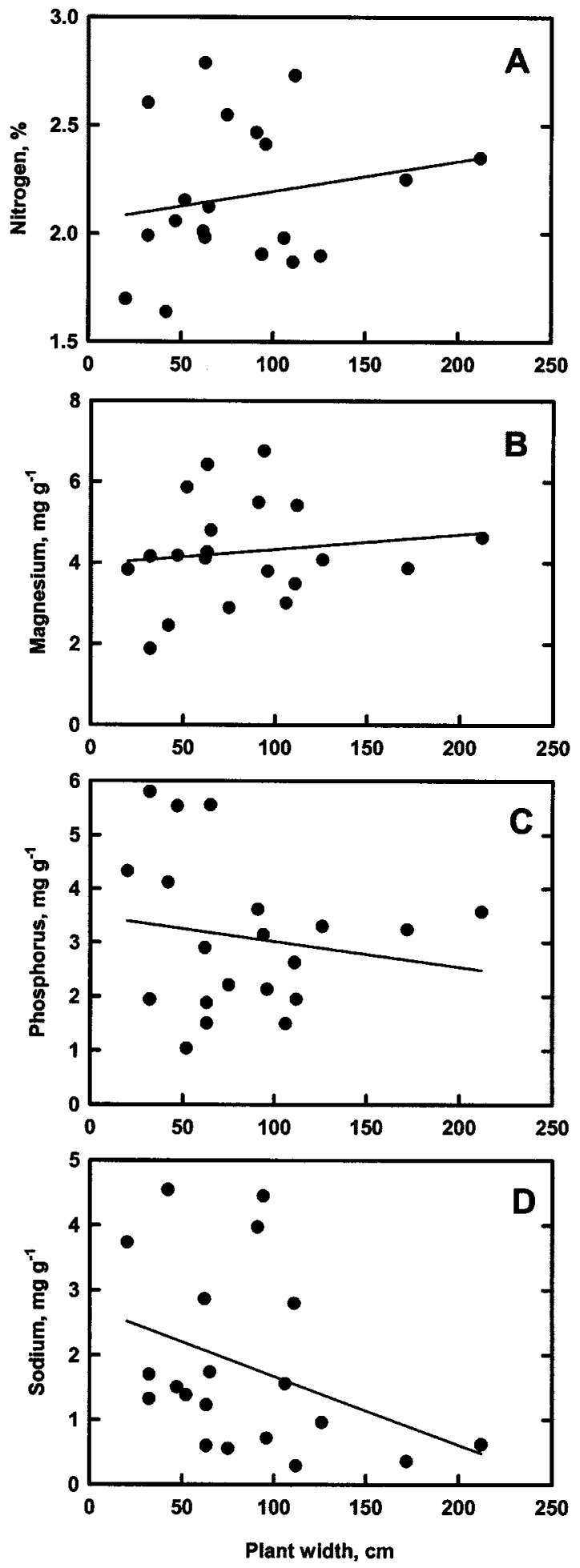

Fig. 5 Percent nitrogen $(A)$ and concentrations of magnesium $(B)$, phosphorus $(C)$, and sodium $(D)$ of tissue at the middle of a frond of individuals of varying sizes of the epiphytic fern Asplenium nidus in a subtropical forest in northeastern Taiwan. Data are expressed on a dry mass basis. Regression analysis yielded the following: $A, y=2.06+$ $0.00138 x, r^{2}=0.04, P=0.4 ; B, y=3.96-0.00367 x, r^{2}=0.02$, $P=0.56 ; \quad C, y=5.9-1.5 x, r^{2}=0.08, P=0.24 ; D, \quad y=2.73-$ $0.0106 x, r^{2}=0.135, P=0.111 . n=20$ plants.

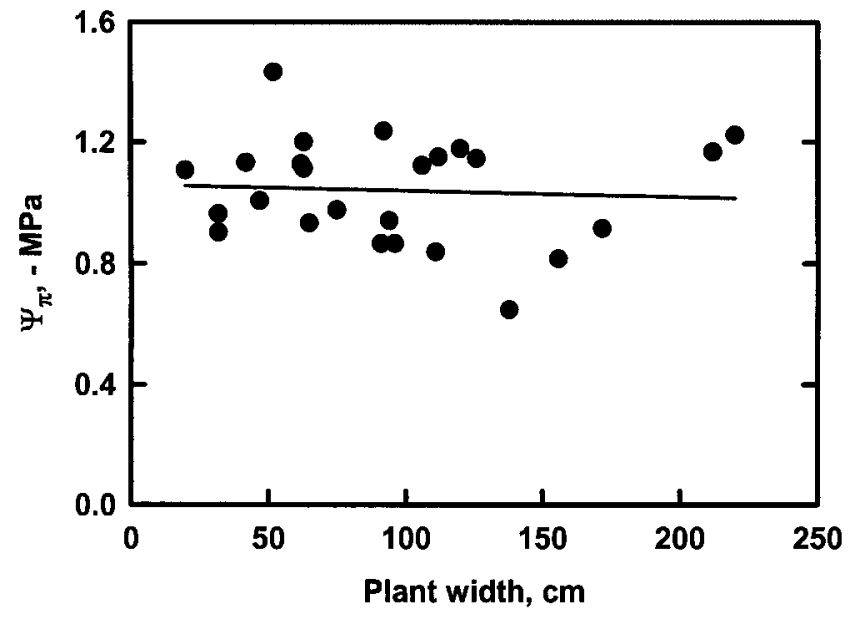

Fig. 6 Osmotic potential of liquid expressed from tissue at the middle of a frond of individuals of varying sizes of the epiphytic fern Asplenium nidus in a subtropical forest in northeastern Taiwan. Regression analysis yielded the following: $y=1.06-0.0002 x$, $r^{2}=0.004, P=0.77 . n=25$ plants.

\section{Frond Osmotic Potential}

Within 15 min of detachment, four 1.2-cm-diameter disks were punched from the middle of a mature frond of average length and frozen at $-10^{\circ} \mathrm{C}$. After at least $24 \mathrm{~h}$, the disks were thawed, then pressed in a vice until a filter paper disk was saturated with the expressed liquid. The osmotic potential of this liquid was then measured with a Wescor Model 5500 Vapor Pressure Osmometer (Logan, Utah) using standards of known osmotic potentials for calibration.

\section{Frond Chlorophyll Concentration}

Within $15 \mathrm{~min}$ of detachment, four 1.2-cm-diameter disks were punched from the middle of a mature frond of average length and placed in $20 \mathrm{~mL}$ of $N, N$-dimethylformamide (DMF). After $2 \mathrm{~d}$ at room temperature, the disks were colorless. The chlorophyll $(a$ and $b$ ) concentration of the DMF solution was measured with a Hach Model DR/3000 spectrophotometer (Loveland, Colo.) according to Moran (1982). The disks were recovered and dried at $70^{\circ} \mathrm{C}$ for a minimum of 1 wk before weighing.

\section{Frond Water Loss}

The bases of fronds were cut underwater, and the cut end was kept underwater during transport to the laboratory (ca. $15 \mathrm{~min}$ ), after which the fronds were placed under fluorescent lamps for $30 \mathrm{~min}$ (cut end still immersed). Then the distal 10-15-cm section of the fronds was excised, weighed, and laid, adaxial side up (supported by an empty styrofoam cup wider than the frond segment), on a lab bench under the same lamps. The fronds were then weighed every $5 \mathrm{~min}$ for 1.5 h. Environmental conditions at frond level were 60-100 $\mu \mathrm{mol} \mathrm{m}{ }^{-2} \mathrm{~s}^{-1} \mathrm{PPFD}, 29^{\circ}-30^{\circ} \mathrm{C}$, ca. $70 \% \mathrm{RH}$, and $380-420$ ppm $\mathrm{CO}_{2}$. After the desiccation period, the fronds were placed in an oven at $70^{\circ} \mathrm{C}$ for at least a week before weighing. 

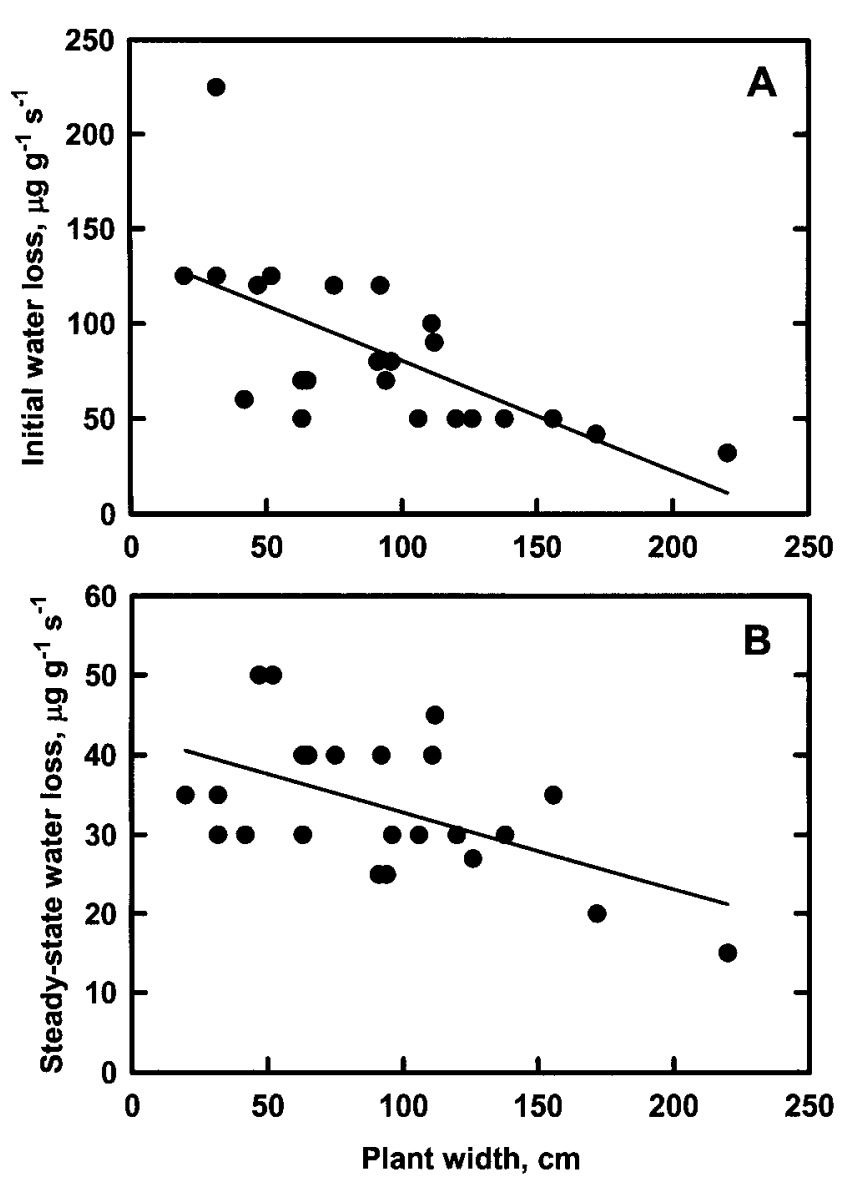

Fig. 7 Rates of water loss, early in a laboratory desiccation experiment when rates were high $(A)$ and later when rates were low $(B)$, of excised fronds of individuals of varying sizes of the epiphytic fern Asplenium nidus in a subtropical forest in northeastern Taiwan. Data are expressed on a dry mass basis. Regression analysis yielded the following: $A, y=138-0.579 x, r^{2}=0.43, P=0.001 ; B, y=$ $42.5-0.0967 x, r^{2}=0.294, P=0.008 . n=23$ plants.

\section{In Situ Frond Gas Exchange}

Gas $\left(\mathrm{CO}_{2}\right.$ and $\mathrm{H}_{2} \mathrm{O}$ vapor) exchange of a $2 \times 2-\mathrm{cm}$ area in the middle of a mature frond of average length was measured in situ using a LI-COR LI-6400 Portable Photosynthesis System under the following controlled conditions: $500 \mu \mathrm{mol}$ $\mathrm{m}^{-2} \mathrm{~s}^{-1}$ PPFD (red and blue diodes), $27^{\circ}-30^{\circ} \mathrm{C}$ leaf temperature, $70 \%-80 \% \mathrm{RH}$, and $360-380 \mathrm{ppm} \mathrm{CO}_{2}$ concentration. Several prior photosynthesis-PPFD curves indicated that 500 $\mu \mathrm{mol} \mathrm{m}{ }^{-2} \mathrm{~s}^{-1}$ PPFD was a near-saturating light level. Environmental conditions outside the gas exchange chamber varied from plant to plant depending on cloud position, shading by surrounding vegetation, and time of day (all measurements were taken between 1000 and 1700 hours). Data were collected only when gas exchange reached a steady state level, which typically took $15 \mathrm{~min}$.

\section{Statistical Analysis}

All morphological and physiological data were analyzed as regressions with plant width as the independent variable (Sokal and Rohlf 1981). Statistically significant regressions were inferred when $P \leq 0.05$. Graphing and statistical analyses were performed using the software programs SigmaPlot (SPSS, Chicago) and Minitab (State College, Pa.), respectively.

\section{Results and Discussion}

Plant widths of individuals of the epiphytic fern Asplenium nidus included in this study ranged by over an order of magnitude (fig. 1). Plants were selected with similar exposures and canopy openness (gap fraction). As a result, values of canopy openness (percent canopy light) were not associated with plant size (fig. 1). Thus, it was assumed in this study that environmental conditions at the microsite of each individual were not too dissimilar.

Unlike results from a previous study with an epiphytic bromeliad (Schmidt and Zotz 2001), frond thickness did not vary with plant size in $A$. nidus (fig. 2). Furthermore, stomatal dimensions did not change as plant size varied (fig. $3 A$, $3 B$ ). However, stomatal densities on the abaxial surfaces of
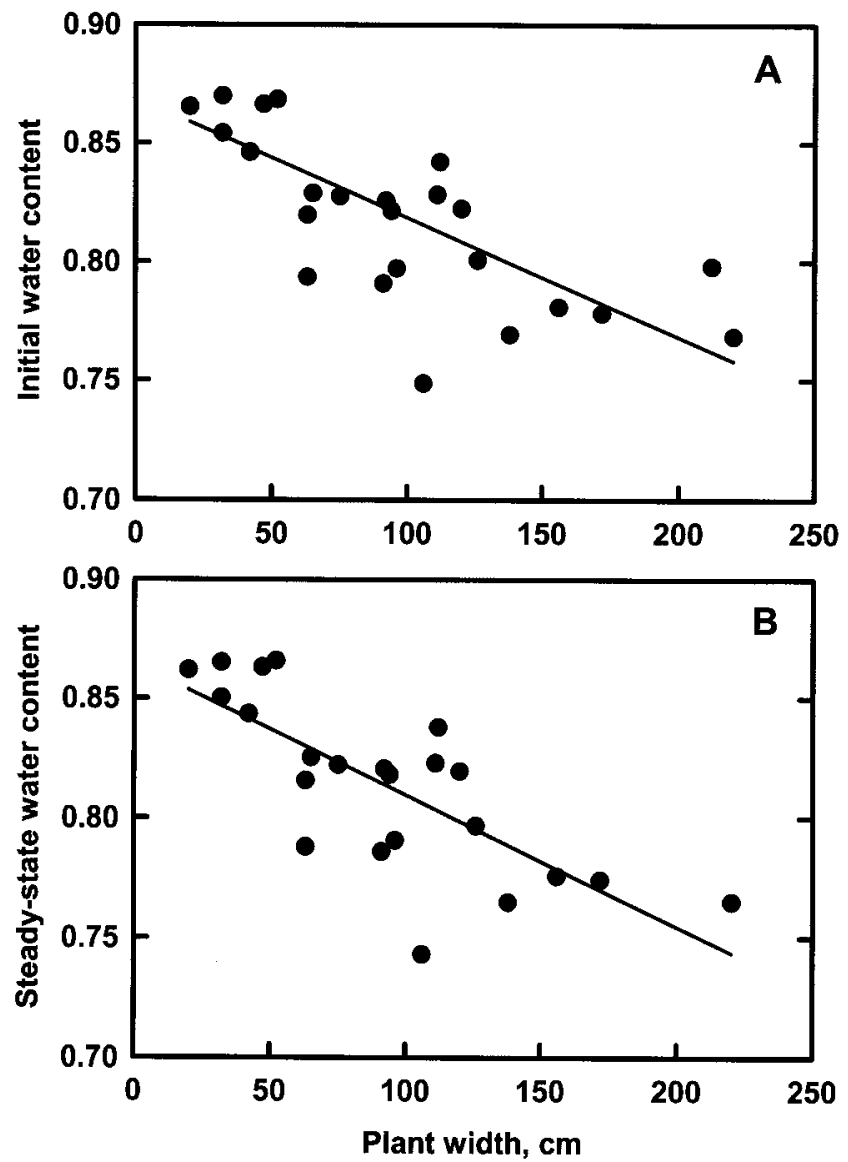

Fig. 8 Water content, early in a laboratory desiccation experiment when water loss rates were high $(A)$ and later when rates were low $(B)$, of excised fronds of individuals of varying sizes of the epiphytic fern Asplenium nidus in a subtropical forest in northeastern Taiwan. Water content is defined as (fresh mass - dry mass)/fresh mass. Regression analysis yielded the following: $A, y=0.865-0.00055 x, r^{2}=0.57$, $P=0.000 ; B, y=0.869-0.00051 x, r^{2}=0.49, P=0.000 . n=23$ plants. 

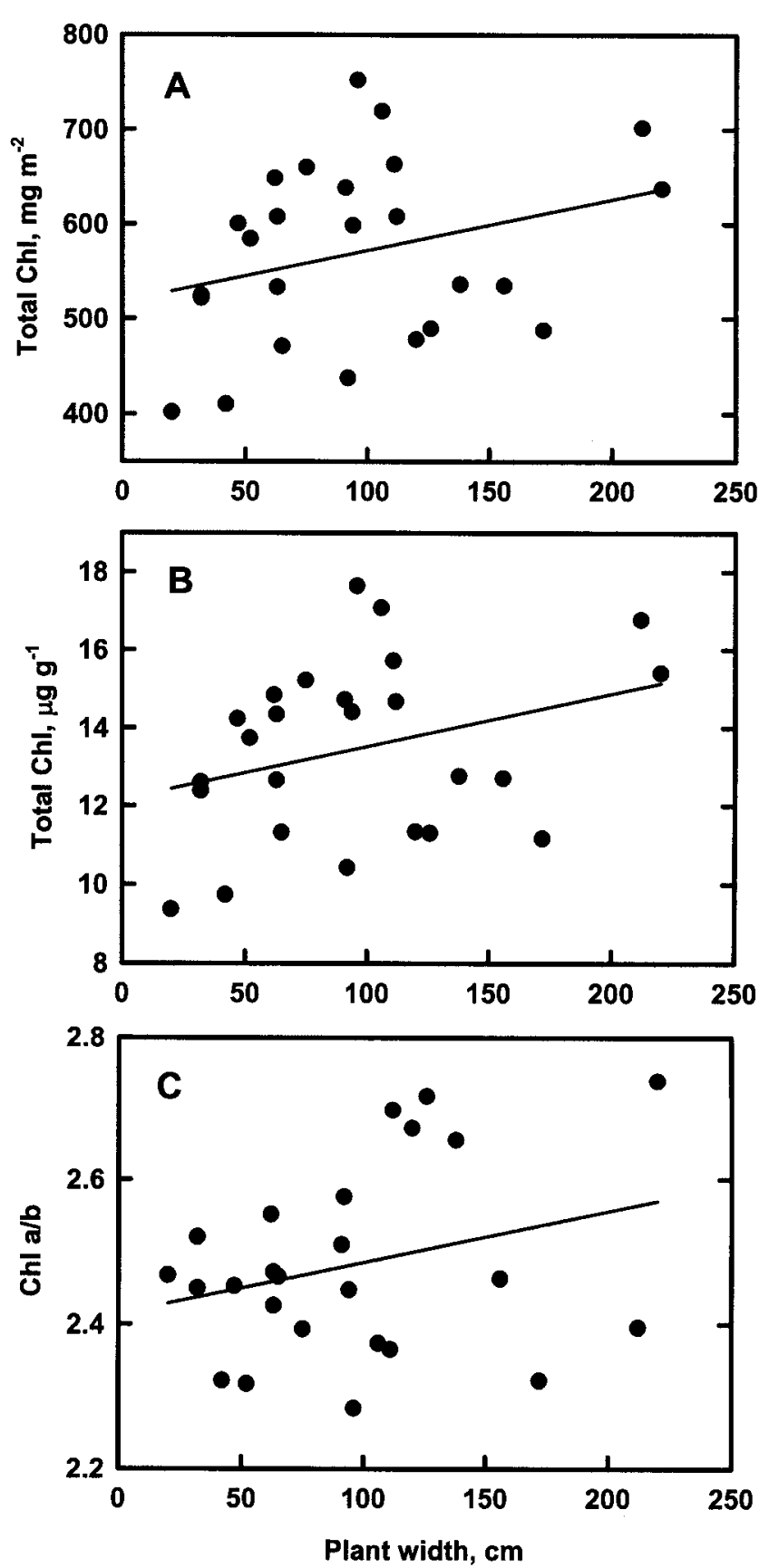

Fig. 9 Chlorophyll concentrations, on an area basis $(A)$ and on a dry mass basis $(B)$, and $a / b$ ratios $(C)$ of tissue at the middle of a frond of individuals of varying sizes of the epiphytic fern Asplenium nidus in a subtropical forest in northeastern Taiwan. Regression analysis yielded the following: $A, y=518+0.539 x, r^{2}=0.09, P=$ $0.147 ; B, y=12.2+0.0135 x, r^{2}=0.1, P=0.122 ; C, y=2.41+$ $0.0007 x, r^{2}=0.08, P=0.167 . n=25$ plants.

the fronds (there were no stomata on the adaxial surfaces) increased with an increase in plant size (fig. 3C). Although larger plants clearly had larger leaves (longer and wider; data not shown), these results cannot be ascribed to simple expansion of the fronds because the opposite findings would result. Schmidt and Zotz (2001) also found a positive correlation between stomatal density and plant size in the epiphytic bromeliad Vriesea sanguinolenta.

While the percent carbon of the fronds of A. nidus increased with increasing plant size, the calcium and potassium concentrations of the fronds decreased as plant width increased in this epiphytic fern (fig. 4). In contrast, frond nitrogen, magnesium, phosphorus, and sodium concentrations were not related to plant size (fig. 5). An increase in percent carbon might reflect an increase in structural support in the larger fronds. Although the declines in frond potassium and calcium concentrations might be ascribed to the increase in frond percent carbon as plant size increased, this explanation is difficult to support in light of the lack of a relationship between the frond concentrations of the other elements and plant size. Overall, the elemental data for A. nidus do not support past findings with other epiphytes in which the nitrogen concentrations of leaves of larger plants were greater than those of smaller plants (Schmidt et al. 2001).

The osmotic potential of the cellular liquid expressed from the fronds of $A$. nidus did not vary as plant size increased more than 10-fold (fig. 6). Osmotic potential values of all plants were consistently high, between -0.6 and $-1.5 \mathrm{MPa}$, as has been reported for other epiphytes (Harris 1918; Martin 1994). Such high values (close to $0 \mathrm{MPa}$ ) in plants exposed to frequent drought stress, a result of often unreliable sources of water in the epiphytic microhabitat, are puzzling and in need of further investigation (Martin 1994; Zotz and Hietz 2001; Martin et al., in press). Although highly negative osmotic potentials and, hence, water potentials may not be advantageous for epiphytes when pure water is abundantly available during rains, high osmotic potentials would appear to limit the range of tissue water potentials possible and, as a result, limit productivity during periods of drought (Zotz and Hietz 2001).

Previous investigation of the rates of water loss from detached leaves of the epiphytic bromeliad V. sanguinolenta indicated that smaller individuals exhibited higher water contents on stomatal closure and lower transpiration rates following stomatal closure during laboratory experiments (Schmidt and Zotz 2001). Similar results, at least in part, were found in this study. Although water loss rates, either initial or later in the period of frond desiccation, were higher in leaves of smaller plants (fig. 7), initial tissue water contents were higher in the fronds collected from the smaller plants (fig. 8). Thus, fronds from smaller plants contained more water at the start of the drying experiment, which could explain their higher rates of water loss. The higher water contents measured later in the frond desiccation treatment might reflect earlier stomatal closure, as reported by Schmidt and Zotz (2001), although the higher rates of water loss at this time are difficult to reconcile with this explanation. There are two reasons it was considered unlikely that the water losses observed in this experiment resulted from exposure of internal tissue at the cut ends of the fronds. First, the fronds were very thin (fig. 2), thus exposing little internal tissue to the atmosphere at the cut ends. Second, water losses were lower in fronds from the larger plants, yet these fronds were substantially wider than fronds from smaller plants, which should have exposed a larger amount of wet, internal tissue at the cut ends. 
As plant width increased, chlorophyll concentration of the fronds, on an area or mass basis, appeared to increase, although the results were not statistically significant (fig. 9A, $9 B$ ). A similar trend was found for chlorophyll $a / b$ ratios (fig. 9C). If a greater sample size supported greater chlorophyll concentrations in fronds of the larger plants, these results might indicate that the larger plants grew in locations with less sunlight, because higher chlorophyll concentrations often characterize shade-adapted leaves (Boardman 1977; Björkman 1981). Such results might indicate that the larger epiphytes were more frequently shaded, despite the similarity in canopy openness of the habitat of these epiphytes (fig. 1). It is likely that the fronds of the larger plants experienced greater degrees of self-shading from fronds growing above those sampled (fronds were always taken at the vertical midpoint of the epiphytes). Schmidt and Zotz (2001) also reported no effect of plant size on leaf chlorophyll concentrations and $a / b$ ratios in an epiphytic bromeliad.

Rates of net $\mathrm{CO}_{2}$ exchange, measured under controlled environmental conditions yet in situ, of attached leaves on individuals of $A$. nidus were very low (fig. 10A) and were typical of many epiphytic taxa (Martin 1994; Schmidt and Zotz 2001). Surprisingly, net $\mathrm{CO}_{2}$ exchange rates of several individuals were negative. Plant water status was not determined in this study, and it is likely that some plants were desiccated because no rain occurred during the time of measurements; only $1.1 \mathrm{~cm}$ of rain fell during the previous $8 \mathrm{~d}$. If this were the case, these findings, if significant, would support the hypothesis of Zotz and coworkers that smaller individuals of tank epiphytes should desiccate more quickly than larger individuals (Schmidt and Zotz 2001; Zotz et al. 2001a). Because $A$. nidus does not trap water at its leaf bases as do tank epiphytes, desiccation may pose an even more frequent and devastating problem for this epiphytic fern. Although rates of net $\mathrm{CO}_{2}$ exchange appeared to increase with increasing plant size in this epiphytic fern (fig. 10A), the data were highly variable, and the regression between rates of net $\mathrm{CO}_{2}$ exchange and plant size was not significant. In concordance with this finding, there were no significant relationships between plant size and frond conductance to $\mathrm{CO}_{2}$ and the internal $\mathrm{CO}_{2}$ concentration of the fronds (fig. 10B, 10C). These data contrast with those reported by Zotz and coworkers for several species of epiphytes, including an epiphytic fern in a different genus (Schmidt and Zotz 2001; Schmidt et al. 2001; Zotz et al. 2001a, 2001b). They found consistent correlations of photosynthetic capacity with plant size. The lack of a similar significant relationship in $A$. nidus might reflect the uniqueness of this species or could reflect the difference in how photosynthesis was measured in this study relative to those of Zotz and others, i.e., in situ measurements of undisturbed individuals versus laboratory or field measurements of epiphytes that had been removed from their host trees.

The finding of a lack of a significant relationship between gas exchange and plant size (fig. 10) compares favorably with a similar lack of an association between chlorophyll content and plant size (fig. 9) in this epiphytic fern. The finding of increased stomatal density in fronds of larger plants (fig. 3), however, is difficult to rectify with the lower transpiration rates of fronds detached from larger plants (fig. 7) and with
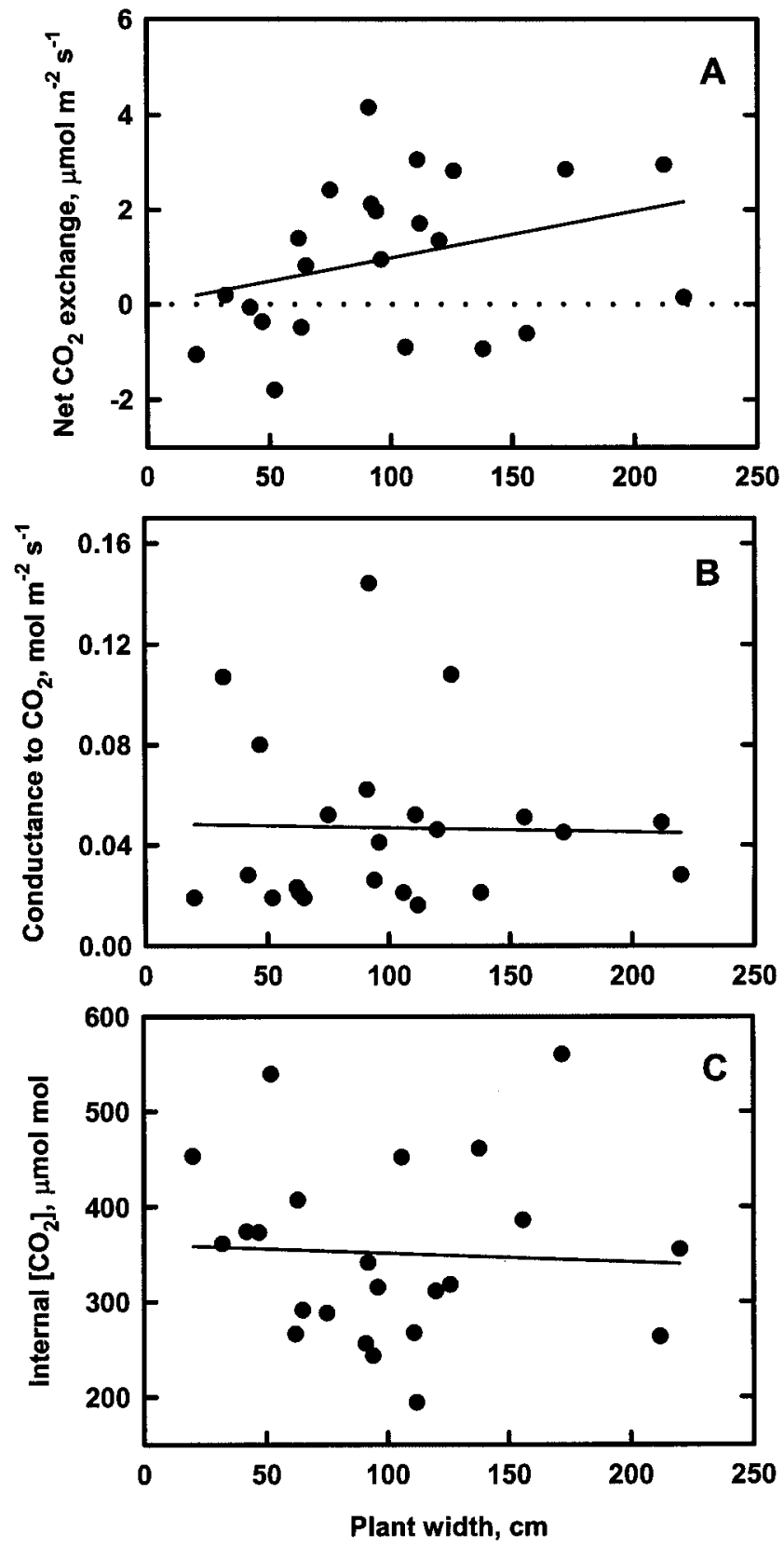

Fig. 10 Net $\mathrm{CO}_{2}$ exchange $(A)$, conductance to $\mathrm{CO}_{2}(B)$, and internal $\mathrm{CO}_{2}$ concentration $(C)$ measured in situ at the middle of a frond of individuals of varying sizes of the epiphytic fern Asplenium nidus in a subtropical forest in northeastern Taiwan. Regression analysis yielded the following: $A, y=-0.005+0.0099 x, r^{2}=0.104$, $P=0.134 ; B, y=0.0485-0.000017 x, r^{2}=0.001, P=0.905 ; C$, $y=360-0.094 x, r^{2}=0.003, P=0.811 . n=23$ plants.

the lack of a significant relationship between stomatal conductances of fronds and plant size in the field measurements of gas exchange (fig. 10). Of course, the observed differences in stomatal density can be easily offset by differences in stomatal apertures in the lab and in the field.

Overall, the results of this investigation of the effect of plant size on morphological and physiological parameters in 
the epiphytic fern A. nidus lend little support to previous findings and concerns about the potential effects of plant size on the ecophysiology of epiphytes. Although some morphological and physiological measures were related to plant size, many other morphological and physiological parameters were not associated with plant size in this epiphytic fern. More work with other epiphytic and terrestrial species is required before generalizations can be widely applied. In addition, clarification of the potential mechanisms underlying size-related differences in the physiology of plants is wanting.

\section{Acknowledgments}

Assistance in the field was graciously provided by Ya-Hui Chang, Jih-horng Chunaung, Chao Hui-te, and Gene-Sheng Tung. Nutrient analyses of the fronds were kindly provided by C. P. Wang, and expert statistical advice was cheerfully offered by John Kelly. We extend special thanks to Yi-Tzeng Her and Yau-tz Tang for making the in situ gas exchange measurements. Financial assistance (project NSC90-2621-B018-001-A10) from the National Science Council (Taiwan) is gratefully acknowledged.

\section{Literature Cited}

Björkman O 1981 Responses to different quantum flux densities. Pages 57-107 in OL Lange, PS Nobel, CB Osmond, H Ziegler, eds. Physiological plant ecology. Vol 1. Responses to the physical environment. Springer, Berlin.

Boardman NK 1977 Comparative photosynthesis of sun and shade plants. Annu Rev Plant Physiol 28:355-377.

Grulke NE, PR Miller 1994 Changes in gas exchange characteristics during the life span of giant sequoia: implications for response to current and future concentrations of atmospheric ozone. Tree Physiol 14:659-668.

Grulke NE, WA Retzlaff 2001 Changes in physiological attributes of ponderosa pine from seedling to mature tree. Tree Physiol 21:275-286.

Harris JA 1918 On the osmotic concentration of the tissue fluids of phanerogamic epiphytes. Am J Bot 5:490-506.

Huang T-C 1994 Flora of Taiwan. 2d ed. Vol 1. Editorial Committee of the Flora of Taiwan, Taipei. 648 pp.

Kolb TE, JE Stone 2000 Differences in leaf gas exchange and water relations among species and tree sizes in an Arizona pine-oak forest. Tree Physiol 20:1-12.

Kull O, A Koppel 1987 Net photosynthetic response to light intensity of shoots from different crown positions and age in Picea abies (L.) Karst. Scand J For Res 2:157-166.

Martin CE 1994 Physiological ecology of the Bromeliaceae. Bot Rev 60:1-82.

Martin CE, T-C Lin, K-C Lin, C-C Hsu, W-L Chion 2004 Causes and consequences of high osmotic potentials in epiphytic higher plants. J Plant Physiol (in press).

Miller PM, LE Eddleman, S Kramer 1990 Allocation patterns of carbon and minerals in juvenile and small-adult Juniperus occidentalis. For Sci 36:734-747.

Moran R 1982 Formulae for determination of chlorophyllous pigments extracted with N,N-dimethylformamide. Plant Physiol 69: 1376-1381.
Ryan MG, RH Waring 1992 Maintenance respiration and stand development in a subalpine lodgepole pine forest. Ecology 73: 2100-2108.

Schmidt G, S Stuntz, G Zotz 2001 Plant size: an ignored parameter in epiphyte ecophysiology? Plant Ecol 153:65-72.

Schmidt G, G Zotz 2001 Ecophysiological consequences of differences in plant size: in situ carbon gain and water relations of the epiphytic bromeliad, Vriesea sanguinolenta. Plant Cell Environ 24: 101-111.

Schoettle AW 1994 Influence of tree size on shoot structure and physiology of Pinus contorta and Pinus aristata. Tree Physiol 14: 1055-1068.

Smith FW, SC Resh 1999 Age-related changes in production and below-ground carbon allocation in Pinus contorta forests. For Sci 45:333-341.

Sokal RR, FJ Rohlf 1981 Biometry: the principles and practice of statistics in biological research. $2 \mathrm{~d}$ ed. WH Freeman, New York. 859 pp.

Yoder BJ, MG Ryan, RH Waring, AW Schoettle, MR Kaufmann 1994 Evidence of reduced photosynthetic rates in old trees. For Sci 40:513-527.

Zotz G 1997 Photosynthetic capacity increases with plant size. Bot Acta 110:306-308.

Zotz G, P Hietz 2001 The physiological ecology of vascular epiphytes: current knowledge, open questions. J Exp Bot 52: 2067-2078.

Zotz G, P Hietz, G Schmidt 2001a Small plants, large plants: the importance of plant size for the physiological ecology of vascular epiphytes. J Exp Bot 52:2051-2056.

Zotz G, V Thomas, W Hartung 2001b Ecophysiological consequences of differences in plant size: abscisic acid relationships in the epiphytic orchid Dimerandra emarginata. Oecologia 129: 179-185. 